\section{Endoscopic submucosal dissection of a nonpolypoid superficial neoplasm of the terminal ileum}

A 73-year-old man underwent colonoscopy for recurrent diffuse abdominal pain. Previous colonoscopy, routine laboratory tests, and a fecal occult blood test had all shown normal results.

At retrograde ileoscopy, a 25-mm laterally spreading tumor, nongranular pseudodepressed type (LST-NG PD; type 0-IIa-IIC according to the Paris classification), was diagnosed $5 \mathrm{~cm}$ proximal to the ileocecal valve ( $\bullet$ Fig. 1). The lesion was characterized as noninvasive by chromoendoscopy and narrow-band imaging using colorectal classifications: it was not villous, the pit pattern was small tubular (type IIIs by Kudo), and the capillary pattern showed thin no-uniform vessels surrounding the crypts (type 3A by Sano) ( $\bullet$ Fig. 2 ).

Endoscopic submucosal dissection (ESD) was performed using a pediatric colono- scope (PCF-Q180AI; Olympus, Japan) and a hood with a small-caliber tip (ST-hood; Fujifilm; Japan) under $\mathrm{CO}_{2}$ insufflation. The procedure started with the incision of the ileal mucosa at the oral side and then moved progressively from the anal to the oral side using a non-insulated knife (Dual knife; Olympus). Diffuse fibrosis ( Fig.3a) and a 2-mm translucent mucus-like nodule ( $\bullet$ Fig. $\mathbf{3 b}, \mathbf{c}$ ) were encountered in the submucosa beneath the lesion during dissection. The ESD was completed en bloc within 100 minutes ( $\bullet$ Fig. 4; $\bullet$ Video 1 ). The resection site was closed using four clips (Resolution clip; Boston Scientific, USA), and no adverse events occurred.
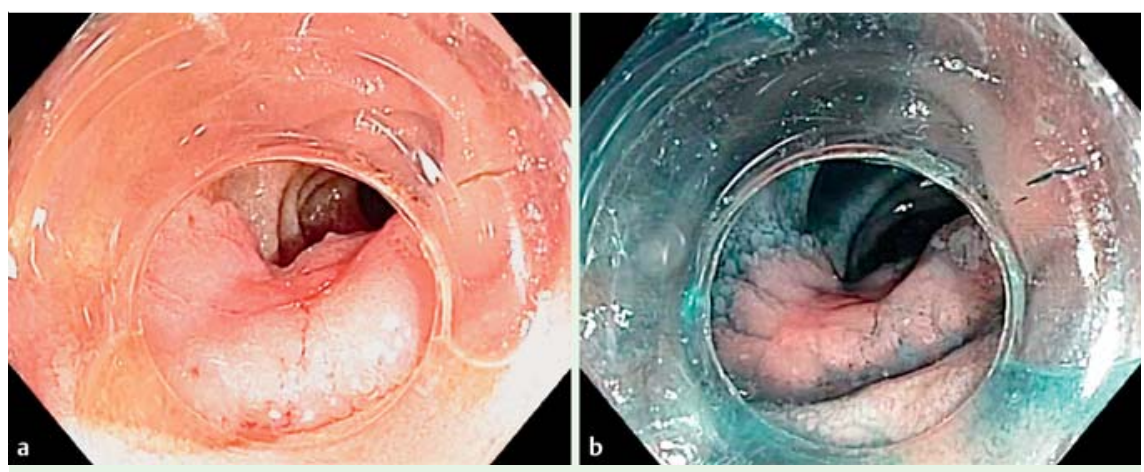

Fig. 1 Endoscopic view showing a laterally spreading tumor of nongranular pseudodepressed type (LST-NG PD) after chromoendoscopy with: a $1 \%$ acetic acid; b $0.4 \%$ indigo carmine.

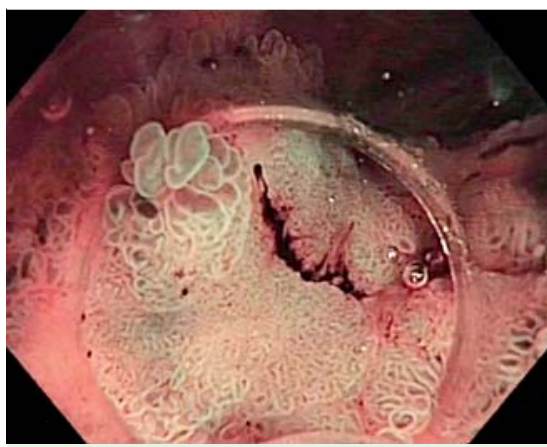

Fig. 2 Endoscopic underwater close-up view showing a microcapillary pattern on narrowband imaging.

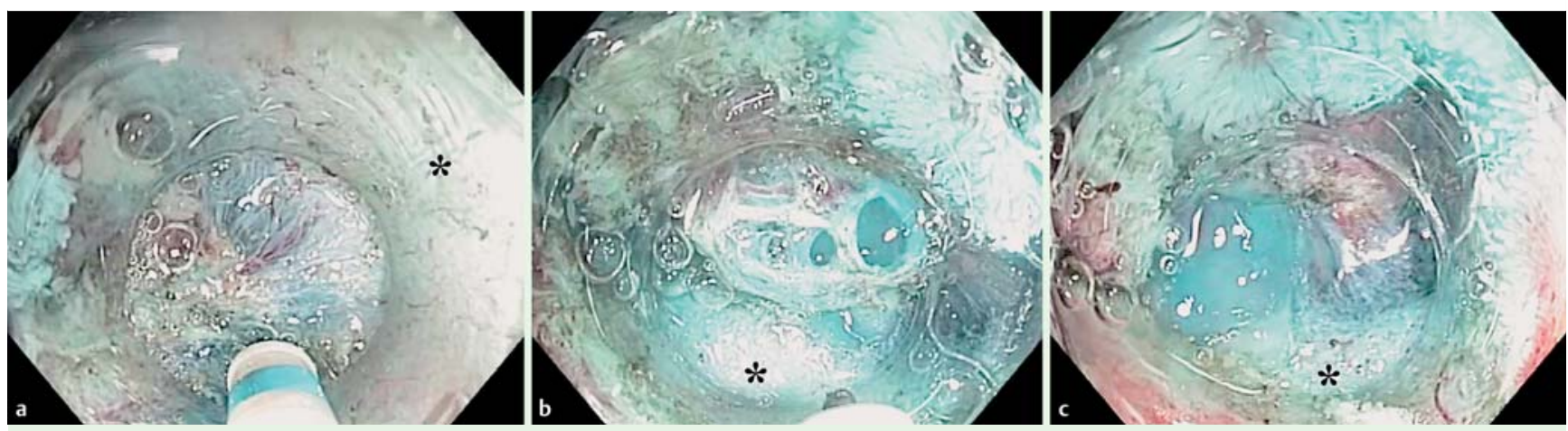

Fig. 3 Views during submucosal dissection showing: a severe fibrosis; $\mathbf{b}$ a 2-mm translucent nodule; $\mathbf{c}$ the nodule after rupture of the pseudocapsule $\left({ }^{*}\right.$ muscularis propria layer).

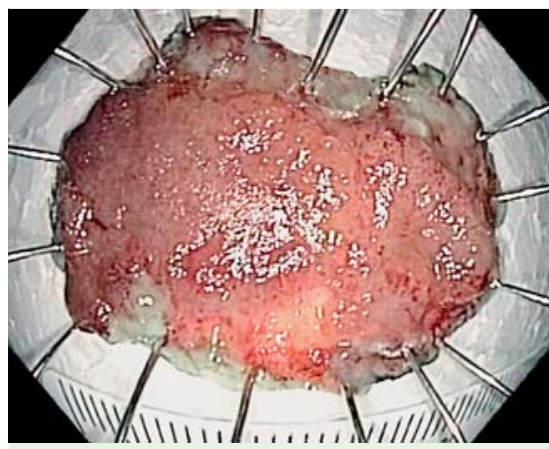

Fig. 4 Macroscopic appearance of the resected specimen $(30 \times 25 \mathrm{~mm})$.

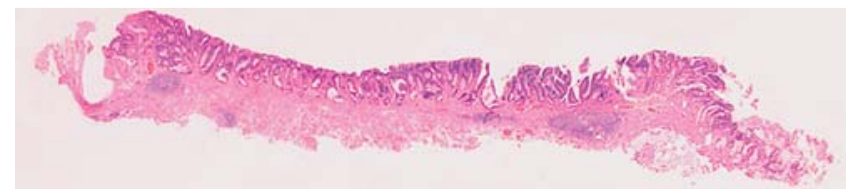

Fig. 5 Histological appearance of the specimen confirming complete curative R0 resection.

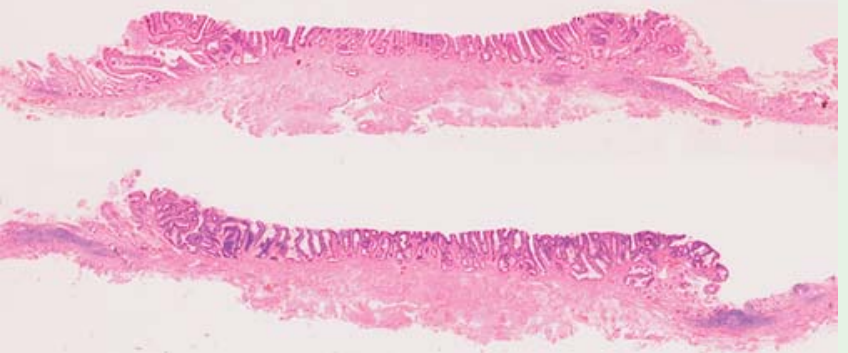




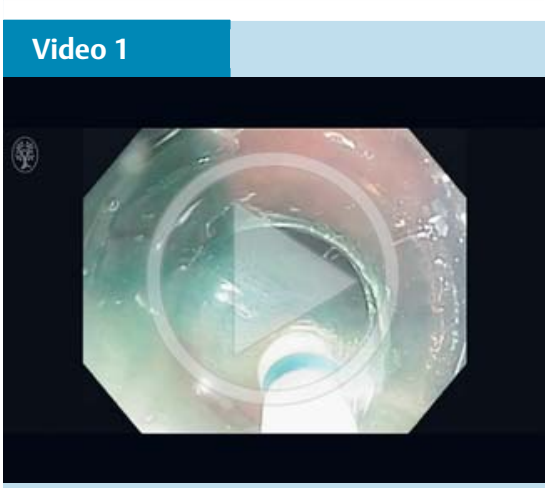

En bloc endoscopic submucosal dissection of a nongranular pseudodepressed laterally spreading tumor (LST-NG PD type) in the terminal ileum.

Histology showed an adenoma with low grade dysplasia and negative lateral and vertical margins ( $\bullet$ Fig.5). The submucosal nodule was interpreted as being a Peyer's patch. Follow-up endoscopy after 6 months revealed no residual tumor and no evidence of a stricture.

Endoscopic resection of superficial neoplasms involving the ileocecal valve and the ileum is difficult and is relatively contraindicated: the conventional piecemeal snare approach is frequently incomplete and requires subsequent surgery even for adenomas and intramucosal cancers [1]. ESD is a new technique that achieves high rates of curative resection but is very rarely adopted in the small bowel, primarily in the duodenum, because of the high technical difficulty and risk of perforation [2-4].

This case reaffirms the need for routine retrograde ileoscopy [5] and indicates that ESD in the terminal ileum is feasible as in other parts of the gastrointestinal tract. However, specific technical skills are required to control the deeply inserted endoscope and safely resect a lesion in the narrow, tortuous, mobile and thinwalled small bowel.

Endoscopy_UCTN_Code_TTT_1AQ_2AD

Competing interests: None

\section{Federico lacopini ${ }^{1}$, Yutaka Saito ${ }^{2}$, Takuji Gotoda ${ }^{3}$, Cristina Grossi ${ }^{1}$, Guido Costamagna ${ }^{4}$}

${ }^{1}$ Gastroenterology and Endoscopy Unit, Ospedale S. Giuseppe, Albano L, Rome, Italy

2 Endoscopy Division, National Cancer Center Hospital, Tokyo, Japan

${ }^{3}$ Department of Gastroenterology and Hepatology, Tokyo Medical University, Tokyo, Japan

${ }^{4}$ Surgical Digestive Endoscopy Unit, Policlinico Gemelli, Catholic University, Rome, Italy

\section{References}

1 Sano Y, Machida H, Fu KI et al. Endoscopic mucosal resection and submucosal dissection method for large colorectal tumors. Dig Endosc 2004; 16: S93-S96

2 Kishimoto G, Saito Y, Takisawa H et al. Endoscopic submucosal dissection for large laterally spreading tumors involving the ileocecal valve and terminal ileum. World J Gastroenterol 2012; 18: $291-294$

3 Nonaka S, Oda I, Tada $\mathrm{K}$ et al. Clinical outcomes of endoscopic resection for nonampullary duodenal tumors. Endoscopy 2015; 47: 129-135

4 Sasajima K, Chinzei R, Takahashi M et al. Endoscopic submucosal dissection for an early ileal cancer. Gastrointest Endosc 2015; 81: $1031-1032$

5 Iacopini G, Frontespezi S, Vitale MA et al. Routine ileoscopy at colonoscopy: a prospective evaluation of learning curve and skill-keeping line. Gastrointest Endosc 2006; 63: 250-256

\section{Bibliography}

Dol http://dx.doi.org/

10.1055/s-0042-101760

Endoscopy 2016; 48: E57-E58

(C) Georg Thieme Verlag KC

Stuttgart · New York

ISSN 0013-726X

Corresponding author

Federico lacopini, MD

Via T. Mertel 16A

00167 Rome

Italy

federico.iacopini@gmail.com 